Article

\title{
Association of Sensory Liking for Fat with Dietary Intake and Metabolic Syndrome in Korean Adults
}

\author{
Hyeyoung Park ${ }^{\dagger}$, Yoonjin Shin ${ }^{+}$iD, Oran Kwon and Yangha Kim * (iD \\ Department of Nutritional Science and Food Management, Ewha Womans University, Seoul 03760, Korea; \\ hypark1597@naver.com (H.P.); yjin19@hotmail.com (Y.S.); orank@ewha.ac.kr (O.K.) \\ * Correspondence: yhmoon@ewha.ac.kr; Tel.: +82-2-3277-3101 \\ + These authors contributed equally to this work.
}

Received: 30 May 2018; Accepted: 3 July 2018; Published: 6 July 2018

\begin{abstract}
Individual sensory liking is perceived as a major determinant of dietary intake and may influence chronic disease. This study aimed to assess the odds of metabolic syndrome in Korean adults based on their liking for fat. Data from 7731 adults aged 40-69, included in the Korean Genome and Epidemiology Study, were collected. Fat liking scores were obtained from self-report questionnaires. In both genders, sensory liking for fat was positively associated with consumption of red meat and added fat. Subjects with a stronger liking for fat showed a higher intake of energy and fat and a lower intake of vitamin $\mathrm{C}$ and fiber as compared to subjects with a lower liking for fat. There were increasing trends in the odds of metabolic syndrome with stronger liking for fat (odds ratios (ORs) for the Like group compared to the Dislike group, men: ORs $=1.29$ (95\% confidence interval 1.06-1.50) $p$-trend $=0.01$; women: ORs $=1.28(1.04-1.58) p$-trend $=0.018)$ after adjustment for age, alcohol intake, smoking, exercise, education level, and income status. Our results suggested that the liking for fat-rich food might partially contribute to the increased odds of metabolic syndrome.
\end{abstract}

Keywords: fat liking; metabolic syndrome; nutrient intake; obesity

\section{Introduction}

Metabolic syndrome is a common disorder associated with increased risk of cardiovascular disease and type 2 diabetes [1]. The predominant risk factors for metabolic syndrome are abdominal obesity and insulin resistance, and other potentially related conditions are physical inactivity, cigarette smoking, and poor diet [2-4]. Although multiple factors influence metabolic syndrome, the syndrome appears to be comparatively rare when there is no excess body fat [2]. As obesity increases, the prevalence of metabolic syndrome also increases [2]. Obesity thus can be said to be the major driver of the syndrome. Lifestyle changes could reverse metabolic risk, and dietary habits are considered an important factor affecting the prevention of metabolic syndrome.

Fat is universally preferred since it can provide a palatable flavor and a soft and crisp texture when mixed with other ingredients. Liking for fat often leads to the consumption of high-calorie foods, such as butter, meat, and fatty-sweet products $[5,6]$. Fatty foods give a sense of pleasure to eating due to the sensory properties they drive, which may encourage their overconsumption [7]. Excessive intake of energy has been reported to be closely associated with major chronic disease, including obesity, cardiovascular disease, and some cancers $[8,9]$.

Previous studies reported a positive association between fat liking and body mass index (BMI) $[10,11]$. Moreover, the study conducted in French population found that adults who liked fat had a significantly increased risk of becoming obese [12]. There was also a positive association between liking for fat and cardiovascular risk factors such as blood pressure [13]. Liking for fat is supposed to increase the consumption of high-fat and energy-dense foods and is highly likely to cause obesity-related 
metabolic disorders. However, the relationship between liking for fat and metabolic syndrome has yet to be investigated. Thus, the purpose of this study was to investigate the association of fat liking with dietary intake and metabolic syndrome in Korean adults.

\section{Materials and Methods}

\subsection{Subjects}

With the objective of identifying risk factors for chronic disease among Koreans, the Korean Genomic Epidemiology Study (KoGES) implemented health examinations for adult residents aged 40 to 69 years old in the Ansung and Ansan areas, thus representing rural and urban communities, and survey questionnaires were collected [14]. This study used KoGES data surveyed from May 2001 to February 2003. Among the 8840 people (4182 men and 4658 women), those who did not have data related to liking of fat $(n=117)$, body measurements $(n=12)$, blood tests $(n=257)$ or sociodemographic information $(n=362)$ were excluded. Those with a total daily calorie intake that was too high or too low $(<800$ or $>4000 \mathrm{kcal}$ for men, $<500$ or $>3500 \mathrm{kcal}$ for women) were also excluded [15] $(n=361)$. These exclusions left 7731 subjects (3750 men and 3981 women) who were appropriate for the final analysis. This study was approved by the Institutional Review Board of Ewha Womans University (85-4, December 2014), and the procedures followed were in accordance with the Helsinki Declaration of 1975, as revised in 2008.

\subsection{Assessment of Liking for Fat}

Dietary intake was collected by well-trained researchers using a semi-quantitative food frequency questionnaire (SQFFQ). The validation of the SQFFQ was reported previously [16,17]. Dietary data for designing SQFFQ were obtained from the Korea Health and Nutrition Examination Survey (KNHANES) in 1998. Two hundred and forty-nine foods, which were selected based on their 0.9 cumulative percent contribution, and 254 items, which were selected based on their 0.9 cumulative multiple regression coefficients, respectively, were categorized into 97 food groups based on their nutrient composition. Because of the seasonality of the survey, several popular Korean foods missing from the list were included. Subjects indicated the average intake frequency of 103 food items over a period of 12 months (on a 9-point scale of 'almost none', 'once a month', 'twice or three times a month', 'once or twice a week', 'twice or three times a week', 'five or six times a week', 'once a day', 'twice a day', and 'three times a day') and the average intake quantity (on a 3-point scale of small, medium, and large). The researchers presented the pictures of different quantities to the subjects for reference. Favorite cooking method was obtained by asking the subjects how often they had fried food, stir-fried food, seasoned food, and soups and stews (on a 5-point scale of 'almost none', 'once-twice a month', 'once-three times a week', 'four-six times a week', and 'every day'). Then, the results were linearly transformed into values ranging from 0 to 10 , with a high score indicating higher preference. Foods were selected from the list of SQFFQ and were classified into 16 food groups according to previous articles, with slight modification: meat (red meat, processed meat, and chicken), eggs, dairy products, fish and shellfish, seaweeds, grains, potatoes, beans, nuts, fruits, vegetables, mushrooms, added fat, cakes/cookies and chocolates, soft drinks, and other beverages [16]. The food intake determined through the SQFFQ was converted into average intake data for 23 nutrients using the Korean food composition and nutrition table [18]. The nutrient intake obtained by SQFFQ was slightly lower in protein and fat than in dietary records, but total energy and carbohydrate intake were not significantly different [17]. Fat liking was obtained by asking whether the subjects liked fat-rich food [10,19]. The possible answers to this question were 'dislike it very much', 'dislike', 'neither dislike nor like', 'like', and 'like it very much'. Subjects were classified into three groups according to their level of liking for fat: Dislike (dislike it very much and dislike), Neither like nor dislike, and Like (like and like it very much). 


\subsection{Classification of Obesity and Metabolic Syndrome}

According to the World Health Organization's Asia-Pacific Area criterion [20], obesity is indicated by a BMI greater than or equal to $25.0 \mathrm{~kg} / \mathrm{m}^{2}$. The diagnosis of metabolic syndrome was performed based on the diagnostic criteria presented in the 2009 Joint Scientific Statement [21]. Individuals that meet more than three of the following conditions are diagnosed with metabolic syndrome: waist circumference: $\geq 90 \mathrm{~cm}$ for men and $\geq 80 \mathrm{~cm}$ for women according to the recommendation by International Diabetes Federation [3], high-density lipoprotein (HDL) cholesterol $<40 \mathrm{mg} / \mathrm{dL}$ for men and $<50 \mathrm{mg} / \mathrm{dL}$ for women or treatment of dyslipidemia, triglycerides $\geq 150 \mathrm{mg} / \mathrm{dL}$ or treatment of dyslipidemia, systolic and diastolic blood pressure $\geq 130$ and $85 \mathrm{mmHg}$ or antihypertensive treatment, fasting glucose $\geq 100 \mathrm{mg} / \mathrm{dL}$ or treatment of type 2 diabetes.

\subsection{General Characteristics, Anthropometric Measurements, and Biochemical Variables}

General information on gender, age, alcohol consumption (g/day), current smoking (yes, no), moderate-intensity physical activity (yes, no), education status (<high school, $\geq$ high school), and monthly income ( $<2$ million Korean won $(K R W), \geq 2$ million KRW) was collected using an interview administered questionnaire.

The height and weight of the subjects were measured under the condition that each subject took off his or her shoes and clothes and wore only a patient gown. BMI was calculated as weight $(\mathrm{kg}) / \mathrm{height}$ $\left(\mathrm{cm}^{2}\right)$. The circumferences of the waist and hip were measured by non-stretchable standard tape while each subject stood with their legs together and both arms stretched laterally. The circumference of the waist was calculated by measuring the thinnest part of the waist between the ribs and long bone, and the circumference of the hip was estimated by measuring the protruding part of the hip. Each measurement was performed three times to calculate the average values. The waist and hip circumference ratio was also calculated by dividing the waist average value by the hip average value. Blood pressure was measured three times at intervals of 30 safter 5 min of rest, and the average values were calculated and used for the study.

All subjects had their blood samples taken after having fasted for more than 8 hours. The collected blood samples were centrifuged at the site and then analyzed for total cholesterol, HDL cholesterol, triglyceride, hemoglobin $\mathrm{A} 1 \mathrm{c}(\mathrm{HbA} \mathrm{c})$, fasting glucose, and fasting insulin. The homeostasis model assessment of insulin resistance (HOMA-IR) was calculated as fasting insulin $(\mu \mathrm{IU} / \mathrm{mL}) \times$ fasting glucose $(\mathrm{mmol} / \mathrm{L}) / 22.5$ [22]. Low-density lipoprotein (LDL) cholesterol was calculated by the following equations described by Friedewald with triglyceride concentrations $<400 \mathrm{mg} / \mathrm{dL}$ [23]: LDL cholesterol $=[$ Total cholesterol $(\mathrm{mg} / \mathrm{dL})-\{\mathrm{HDL}$ cholesterol $(\mathrm{mg} / \mathrm{dL})-($ Triglycerides $(\mathrm{mg} / \mathrm{dL}) / 5)\}]$.

\subsection{Statistical Analysis}

Analyses were performed separately for men and women, since sex interactions with anthropometric, economic, and lifestyle variables were found. The continuous variables are represented as the mean and standard error (SE) to evaluate the observed variation around the calculated regression line [24]. The trend $p$ was obtained through general linear model analysis and the Cochran-Mantel-Haenszel analysis. The general linear model and the Cochran-Mantel-Haenszel analysis with adjustment for age were used to determine differences in means and distribution of general characteristics and to test for linear trends according to level of liking for fat. Variables that are statistically significant in univariate analysis or known to be potentially important factors related to fat liking were considered as potential confounders, such as age, alcohol intake, smoking, exercise, education level, and income status were adjusted in analyses. For the association between liking for fat and odds of obesity and metabolic syndrome, logistic regression analysis was carried out. All data were analyzed using SAS v9.4 (SAS Institute Inc., Cary, NC, USA) with the significance level set at $p<0.05$. 


\section{Results}

The general characteristics of the subjects are summarized in Table 1 . The number of subjects in the Like group was 857 (22.9\%) for men and 528 (13.3\%) for women. Compared with subjects with a lower liking for fat, men and women with a stronger liking for fat tended to have higher weight. Men with a stronger liking for fat were more likely to drink alcohol and exercise. Women with a stronger liking for fat tended to be younger. In addition, there were significant positive associations between liking for fat and preference fried/stir fried food in men and women.

Food consumption according to level of liking for fat is shown in Table 2. Men and women with a stronger liking for fat tended to have higher intakes of red meat, added fat, and soft drinks, and lower intake of vegetables after adjustment for age, BMI, alcohol intake, smoking, exercise, education level, and income status.

Daily nutritional intake classified by level of liking for fat is shown in Table 3. Men and women with a stronger liking for fat showed significantly higher energy, fat, and cholesterol intake and lower carbohydrate, vitamin C, and fiber intake after adjustment for age, BMI, alcohol intake, smoking, exercise, education level, and income status. They consumed more energy from fat but less from carbohydrates.

Clinical characteristics according to level of liking for fat are shown in Table 4. Compared with subjects with a lower liking for fat, men and women with a stronger liking for fat tended to have higher total cholesterol, LDL cholesterol, waist circumference, and BMI. Men with a stronger liking for fat had higher LDL cholesterol concentrations. Women with a stronger liking for fat had a higher insulin and HOMA-IR.

Table 5 shows the odds for obesity and metabolic syndrome according to level of liking for fat. The overall prevalence of obesity in this subjects was 1530 (40.8\%) for men and 1790 (45.0\%) for women. There was a significant positive association between liking for fat and the odds for obesity in both men and women after adjustment for age, alcohol intake, smoking, exercise, education level, and income status and it was similar to the unadjusted results (Table S1). The odds ratios (ORs) (95\% confidence interval (CI)) comparing the Like versus Dislike groups for obesity were 1.87 (1.58-2.21) in men and 1.72 (1.42-2.08) in women. In addition, the overall prevalence of abdominal obesity and metabolic syndrome in this subjects was 822 (21.9\%) and 760 (20.3\%) for men and 2154 (54.1\%) and 1212 $(30.4 \%)$ for women, respectively. There was a significant positive association between liking for fat and the odds for abdominal obesity; the ORs (95\% CI) for abdominal obesity were 1.91 (1.58-2.31) in men and 1.58 (1.29-1.94) in women. The liking for fat was significantly positively associated with the odds for metabolic syndrome in both men and women after adjustment. The ORs (95\% CI) comparing the Like versus Dislike groups were 1.29 (1.06-1.50) in men and 1.28 (1.04-1.58) in women. 
Table 1. General characteristics of the participants according to the level of liking for fat.

\begin{tabular}{|c|c|c|c|c|c|c|c|c|}
\hline & \multicolumn{4}{|c|}{ Men } & \multicolumn{4}{|c|}{ Women } \\
\hline & $\begin{array}{l}\text { Dislike } \\
(n=1895)\end{array}$ & $\begin{array}{c}\text { Neither Like } \\
\text { nor Dislike } \\
(n=998)\end{array}$ & Like $(n=857)$ & $p$-Trend & $\begin{array}{c}\text { Dislike } \\
(n=2605)\end{array}$ & $\begin{array}{l}\text { Neither Like } \\
\text { nor Dislike } \\
(n=848)\end{array}$ & Like $(n=528)$ & $p$-Trend \\
\hline Age (years) & $51.5(0.2)$ & $50.1(0.3)$ & $52.0(0.3)$ & 0.113 & $53.2(0.2)$ & $49.8(0.3)$ & $51.7(0.4)$ & 0.0003 \\
\hline Height $(\mathrm{cm})$ & $166.8(0.1)$ & $167.4(0.2)$ & $167.3(0.2)$ & 0.016 & $153.7(0.1)$ & $154.3(0.2)$ & $154.2(0.2)$ & 0.608 \\
\hline Weight $(\mathrm{kg})$ & $66.8(0.2)$ & $68.5(0.3)$ & $69.7(0.3)$ & $<0.0001$ & $58.6(0.2)$ & $59.1(0.3)$ & $60.9(0.4)$ & $<0.0001$ \\
\hline Alcohol intake (g/day) & $51.5(0.2)$ & $50.1(0.3)$ & $52.0(0.3)$ & 0.016 & $53.2(0.2)$ & $49.8(0.3)$ & $51.7(0.4)$ & 0.608 \\
\hline Current smoker (\%) & $933(49.2)$ & $476(47.7)$ & $432(50.4)$ & 0.828 & $101(3.9)$ & $16(1.9)$ & $25(4.7)$ & 0.847 \\
\hline Moderate exercise (\%) & $936(49.4)$ & $539(54.0)$ & $458(53.4)$ & 0.026 & $1264(48.5)$ & $417(49.2)$ & $250(47.4)$ & 0.490 \\
\hline Education ( $\geqq$ high school, \%) & $1121(59.2)$ & 641 (64.2) & $481(56.1)$ & 0.589 & $812(31.2)$ & $330(38.9)$ & $181(34.3)$ & 0.618 \\
\hline $\begin{array}{c}\text { Monthly income ( } \geqq 2 \text { million KRW, \%) } \\
\text { Favorite cooking method }\end{array}$ & $835(44.0)$ & $457(45.8)$ & $371(43.3)$ & 0.814 & $801(30.8)$ & $284(33.5)$ & $178(33.7)$ & 0.299 \\
\hline Fried food & $2.3(0.02)$ & $5.0(0)$ & $7.6(0.02)$ & $<0.0001$ & $2.2(0.02)$ & $5.0(0)$ & $7.6(0.02)$ & $<0.0001$ \\
\hline Stir-fried food & $3.9(0.1)$ & $4.1(0.1)$ & $4.4(0.1)$ & $<0.0001$ & $4.1(0.1)$ & $4.4(0.1)$ & $4.8(0.1)$ & $<0.0001$ \\
\hline Seasoned food & $6.2(0.1)$ & $6.0(0.1)$ & $6.4(0.1)$ & 0.061 & $2.7(0.1)$ & $2.6(0.1)$ & $2.8(0.1)$ & 0.220 \\
\hline Soups and stews & $9.3(0.04)$ & $9.2(0.1)$ & $9.3(0.1)$ & 0.919 & $1.8(0.03)$ & $2.1(0.1)$ & $1.9(0.1)$ & 0.226 \\
\hline
\end{tabular}

$\mathrm{KRW}$, Korean won. Values are expressed as means (SE) or number (percentage). The $p$-trend was obtained in general linear model analysis and Cochran-Mantel-Haenszel analysis with adjustment for age. 
Table 2. Food consumption of the participants according to the level of liking for fat.

\begin{tabular}{|c|c|c|c|c|c|c|c|c|}
\hline & \multicolumn{4}{|c|}{ Men } & \multicolumn{4}{|c|}{ Women } \\
\hline & $\begin{array}{c}\text { Dislike } \\
(n=1895)\end{array}$ & $\begin{array}{l}\text { Neither Like } \\
\text { nor Dislike } \\
(n=998)\end{array}$ & Like $(n=857)$ & $p$-Trend & $\begin{array}{c}\text { Dislike } \\
(n=2605)\end{array}$ & $\begin{array}{l}\text { Neither Like } \\
\text { nor Dislike } \\
(n=848)\end{array}$ & Like $(n=528)$ & $p$-Trend \\
\hline Meat (g) & $28.4(0.5)$ & $33.5(0.7)$ & $37.1(0.8)$ & $<0.0001$ & $20.9(0.4)$ & $25.5(0.7)$ & $26.0(0.9)$ & $<0.0001$ \\
\hline Red meat (g) & $24.2(0.4)$ & $28.8(0.6)$ & $31.9(0.7)$ & $<0.0001$ & $17.4(0.3)$ & $21.0(0.6)$ & $20.8(0.8)$ & 0.001 \\
\hline Processed meat (g) & $0.4(0.03)$ & $0.6(0.1)$ & $0.7(0.1)$ & $<0.0001$ & $0.4(0.03)$ & $0.7(0.1)$ & $0.7(0.1)$ & 0.0004 \\
\hline Chicken $(\mathrm{g})$ & $3.7(0.1)$ & $4.1(0.1)$ & $4.5(0.2)$ & $<0.0001$ & $3.1(0.1)$ & $3.9(0.2)$ & $4.5(0.3)$ & $<0.0001$ \\
\hline Eggs $(g)$ & $6.2(0.2)$ & $6.0(0.2)$ & $6.8(0.3)$ & 0.034 & $6.1(0.2)$ & $6.7(0.3)$ & $7.7(0.4)$ & 0.0002 \\
\hline Dairy products $(\mathrm{g})$ & $51.0(1.3)$ & $49.7(1.7)$ & $50.7(2.0)$ & 0.673 & $65.2(1.4)$ & $62.3(2.4)$ & $60.7(2.8)$ & 0.208 \\
\hline Added fat $(\mathrm{g})$ & $0.02(0.004)$ & $0.03(0.005)$ & $0.04(0.006)$ & 0.005 & $0.03(0.003)$ & $0.04(0.01)$ & $0.05(0.01)$ & 0.034 \\
\hline Fish and shellfish (g) & $22.2(0.4)$ & $21.3(0.5)$ & $22.3(0.6)$ & 0.799 & $20.2(0.3)$ & $20.6(0.6)$ & $19.2(0.6)$ & 0.027 \\
\hline Seaweeds (g) & $0.88(0.02)$ & $0.83(0.02)$ & $0.82(0.02)$ & 0.019 & $1.1(0.02)$ & $1.1(0.04)$ & $1.0(0.04)$ & 0.024 \\
\hline Grains (g) & $411.9(1.8)$ & $406.3(2.6)$ & $394.3(2.6)$ & $<0.0001$ & $410.6(1.7)$ & 400.9 (3.2) & $398.0(3.7)$ & 0.024 \\
\hline Potatoes (g) & $8.2(0.2)$ & $7.6(0.3)$ & $7.7(0.3)$ & 0.095 & $12.4(0.3)$ & $11.9(0.5)$ & $11.7(0.6)$ & 0.387 \\
\hline Beans (g) & $17.8(0.3)$ & $16.4(0.4)$ & $17.1(0.4)$ & 0.108 & $19.4(0.3)$ & $17.3(0.5)$ & $17.9(0.7)$ & 0.033 \\
\hline Nuts (g) & $0.4(0.03)$ & $0.5(0.04)$ & $0.4(0.03)$ & 0.664 & $0.33(0.02)$ & $0.33(0.04)$ & $0.40(0.05)$ & 0.22 \\
\hline Fruits (g) & $111.4(2.4)$ & $111.3(3.4)$ & $113.9(4.0)$ & 0.864 & $162.1(3.0)$ & $163.7(5.0)$ & $154.3(6.3)$ & 0.355 \\
\hline Vegetables (g) & $164.1(2.0)$ & $151.7(2.7)$ & $157.2(3.0)$ & 0.021 & $162.2(1.8)$ & $158.9(3.3)$ & $147.7(3.5)$ & 0.001 \\
\hline Mushrooms (g) & $4.1(0.1)$ & $3.8(0.1)$ & $4.2(0.2)$ & 0.924 & $4.4(0.1)$ & $4.0(0.2)$ & 3. $9(0.2)$ & 0.014 \\
\hline Cakes, cookies and chocolates (g) & $4.1(0.2)$ & $4.2(0.2)$ & $4.3(0.2)$ & 0.082 & $3.9(0.1)$ & $4.9(0.3)$ & $6.0(0.4)$ & 0.0004 \\
\hline Soft drinks (g) & $14.0(0.6)$ & $14.5(0.7)$ & $17.3(1.0)$ & 0.001 & $8.5(0.5)$ & $9.8(0.8)$ & $11.5(1.1)$ & 0.041 \\
\hline Other beverage $(\mathrm{g})$ & $35.4(1.1)$ & $34.6(1.3)$ & $31.0(1.4)$ & 0.023 & $33.0(1.2)$ & $29.5(1.7)$ & $27.8(2.1)$ & 0.008 \\
\hline
\end{tabular}

Values were expressed as means (SE). Food consumption was represented as grams per $1000 \mathrm{kcal}$. The $p$-trend was obtained in general linear model analysis with adjustment for age, body mass index, alcohol intake, smoking, exercise, education level, and income status. 
Table 3. Nutritional status of the participants according to the level of liking for fat.

\begin{tabular}{|c|c|c|c|c|c|c|c|c|}
\hline & \multicolumn{4}{|c|}{ Men } & \multicolumn{4}{|c|}{ Women } \\
\hline & $\begin{array}{c}\text { Dislike } \\
(n=1895)\end{array}$ & $\begin{array}{c}\text { Neither Like } \\
\text { nor Dislike } \\
(n=998)\end{array}$ & Like $(n=857)$ & $p$-Trend & $\begin{array}{c}\text { Dislike } \\
(n=2605)\end{array}$ & $\begin{array}{c}\text { Neither Like } \\
\text { nor Dislike } \\
(n=848)\end{array}$ & Like $(n=528)$ & $p$-Trend \\
\hline $\begin{array}{l}\text { Total energy intake (kcal) } \\
\text { Nutrient intake }\end{array}$ & $1947.8(11.5)$ & $2000.7(17.3)$ & $2111.5(18.8)$ & $<0.0001$ & $1771.4(9.9)$ & $1829.6(18.1)$ & $1943.6(24.0)$ & $<0.0001$ \\
\hline Carbohydrate $(\mathrm{g})$ & $334.3(0.6)$ & $329.9(0.9)$ & $326.5(1.1)$ & $<0.0001$ & $341.2(0.6)$ & $336.5(1.1)$ & $336.6(1.3)$ & 0.018 \\
\hline Protein $(\mathrm{g})$ & $64.4(0.2)$ & $64.5(0.3)$ & $65.5(0.4)$ & 0.008 & $64.1(0.2)$ & $64.3(0.4)$ & $63.6(0.4)$ & 0.076 \\
\hline Fat $(\mathrm{g})$ & $31(0.2)$ & $32.9(0.3)$ & $33.7(0.3)$ & $<0.0001$ & $28.9(0.2)$ & $31.2(0.4)$ & $30.8(0.5)$ & 0.005 \\
\hline Cholesterol (g) & $165.7(2.2)$ & $166(3.0)$ & $173.4(3.1)$ & 0.029 & $168.6(2.3)$ & $178.2(4.2)$ & $176.8(5.0)$ & 0.315 \\
\hline Vitamin C (g) & $113.5(1.3)$ & $107.9(1.7)$ & $108(1.9)$ & 0.007 & $134.6(1.5)$ & $132.7(2.6)$ & $123.8(2.9)$ & 0.002 \\
\hline Fiber (mg) & $6.7(0.05)$ & $6.3(0.1)$ & $6.4(0.1)$ & 0.0003 & $7.3(0.05)$ & $7.0(0.1)$ & $6.9(0.1)$ & $<0.0001$ \\
\hline Energy distribution & & & & & & & & \\
\hline Carbohydrate (\% of total energy) & $70.5(0.1)$ & $69.4(0.2)$ & $68.2(0.2)$ & $<0.0001$ & $72.7(0.1)$ & $71.5(0.2)$ & $71.0(0.3)$ & $<0.0001$ \\
\hline Protein (\% of total energy) & $13.6(0.1)$ & $13.6(0.1)$ & $13.9(0.1)$ & $<0.0001$ & $13.3(0.1)$ & $13.4(0.1)$ & $13.4(0.1)$ & 0.699 \\
\hline Fat ( $\%$ of total energy) & $14.8(0.1)$ & $15.8(0.2)$ & $16.7(0.2)$ & $<0.0001$ & $13.0(0.1)$ & $14.2(0.2)$ & $14.6(0.2)$ & $<0.0001$ \\
\hline
\end{tabular}

Values were expressed as means (SE). Nutrients were adjusted for total energy intake using residual method. The $p$-trend was obtained in general linear model analysis with adjustment for age, body mass index, alcohol intake, smoking, exercise, education level, and income status.

Table 4. Clinical characteristics of the participants according to the level of liking for fat.

\begin{tabular}{|c|c|c|c|c|c|c|c|c|}
\hline & \multicolumn{4}{|c|}{ Men } & \multicolumn{4}{|c|}{ Women } \\
\hline & $\begin{array}{c}\text { Dislike } \\
(n=1895)\end{array}$ & $\begin{array}{l}\text { Neither Like } \\
\text { nor Dislike } \\
(n=998)\end{array}$ & Like $(n=857)$ & $p$-Trend & $\begin{array}{c}\text { Dislike } \\
(n=2605)\end{array}$ & $\begin{array}{c}\text { Neither Like } \\
\text { nor Dislike } \\
(n=848)\end{array}$ & Like $(n=528)$ & $p$-Trend \\
\hline Total cholesterol (mg/dL) & $197.8(0.8)$ & $200.7(1.1)$ & $202.9(1.2)$ & 0.019 & $199.7(0.7)$ & $196.5(1.2)$ & $204.8(1.6)$ & 0.004 \\
\hline HDL cholesterol (mg/dL) & $47.5(0.3)$ & $47.7(0.4)$ & $47.8(0.4)$ & 0.005 & $50.7(0.2)$ & $51.9(0.4)$ & $51.3(0.5)$ & 0.075 \\
\hline LDL cholesterol (mg/dL) & $118.4(0.8)$ & $121.3(1.1)$ & $122.6(1.2)$ & 0.01 & $122.0(0.6)$ & $118.9(1.1)$ & $127.0(1.4)$ & 0.001 \\
\hline Triglycerides (mg/dL) & $169.4(2.9)$ & $168.0(3.9)$ & $175.3(4.3)$ & 0.321 & $137.7(1.8)$ & $131.2(2.9)$ & $137.8(3.9)$ & 0.544 \\
\hline Glucose $(\mathrm{mg} / \mathrm{dL})$ & $95.2(0.6)$ & $95.3(0.7)$ & $95.2(0.8)$ & 0.409 & $90.2(0.4)$ & $90.2(0.8)$ & $92.7(1.3)$ & 0.085 \\
\hline Insulin $(\mu \mathrm{IU} / \mathrm{mL})$ & $6.9(0.1)$ & $7.2(0.1)$ & $7.3(0.2)$ & 0.858 & $7.8(0.1)$ & $8.1(0.2)$ & $8.5(0.2)$ & 0.027 \\
\hline HOMA-IR (mg/dL) & $1.65(0.02)$ & $1.72(0.04)$ & $1.74(0.04)$ & 0.839 & $1.75(0.02)$ & $1.83(0.04)$ & $1.97(0.06)$ & 0.005 \\
\hline Systolic blood pressure (mmHg) & $116.6(0.4)$ & $116.5(0.5)$ & $117.2(0.5)$ & 0.673 & $117.3(0.4)$ & $114.6(0.7)$ & $117.3(0.9)$ & 0.097 \\
\hline Diastolic blood pressure (mmHg) & $75.9(0.3)$ & $76.3(0.4)$ & $75.9(0.4)$ & 0.896 & $73.7(0.2)$ & $73.1(0.4)$ & $73.9(0.6)$ & 0.121 \\
\hline Waist circumference $(\mathrm{cm})$ & $82.7(0.2)$ & $84.1(0.2)$ & $85.1(0.3)$ & $<0.0001$ & $81.0(0.2)$ & $80.8(0.3)$ & $82.8(0.4)$ & $<0.0001$ \\
\hline Body mass index $\left(\mathrm{kg} / \mathrm{m}^{2}\right)$ & $24.0(0.1)$ & $24.4(0.1)$ & $24.9(0.1)$ & $<0.0001$ & $24.8(0.1)$ & $24.8(0.1)$ & $25.6(0.1)$ & $<0.0001$ \\
\hline
\end{tabular}

HDL, high-density lipoprotein; LDL, low-density lipoprotein; HOMA-IR, homeostasis model assessment of insulin resistance. Values were expressed as means (SE). The $p$-trend was obtained in general linear model analysis with adjustment for age, alcohol intake, smoking, exercise, education level, and income status. 
Table 5. Odds ratios (95\% confidence intervals) for obesity and metabolic syndrome according to level of liking for fat.

\begin{tabular}{|c|c|c|c|c|c|c|c|c|}
\hline & \multicolumn{4}{|c|}{ Men } & \multicolumn{4}{|c|}{ Women } \\
\hline & $\begin{array}{c}\text { Dislike } \\
(n=1895)\end{array}$ & $\begin{array}{l}\text { Neither Like } \\
\text { nor Dislike } \\
(n=998)\end{array}$ & Like $(n=857)$ & $p$-Trend & $\begin{array}{c}\text { Dislike } \\
(n=2605)\end{array}$ & $\begin{array}{l}\text { Neither Like } \\
\text { nor Dislike } \\
(n=848)\end{array}$ & Like $(n=528)$ & $p$-Trend \\
\hline \multicolumn{9}{|l|}{ Low HDL cholesterol } \\
\hline Prevalence (n (\%)) & $427(24.9)$ & $238(23.9)$ & $225(26.3)$ & & $1342(51.5)$ & $396(46.7)$ & $270(51.1)$ & \\
\hline ORs $(95 \% \mathrm{CI})$ & 1 & $0.86(0.71-1.04)$ & $0.94(0.77-1.14)$ & $0.346 *$ & 1 & $0.85(0.72-1.00)$ & $0.92(0.76-1.11)$ & $0.135 *$ \\
\hline \multicolumn{9}{|l|}{ Hypertriglyceridemia } \\
\hline Prevalence (n (\%)) & $811(42.8)$ & $447(44.8)$ & $404(47.1)$ & & $796(30.6)$ & $236(27.8)$ & $166(31.4)$ & \\
\hline ORs $(95 \%$ CI $)$ & 1 & $0.98(0.83-1.15)$ & $0.97(0.82-1.15)$ & $0.715 *$ & 1 & $1.03(0.86-1.24)$ & $0.98(0.79-1.21)$ & $0.956 *$ \\
\hline \multicolumn{9}{|l|}{ High fasting glucose } \\
\hline Prevalence (n (\%)) & $411(21.7)$ & $215(21.5)$ & $178(20.8)$ & & $336(12.9)$ & $103(12.2)$ & 77 (14.6) & \\
\hline ORs $(95 \%$ CI $)$ & 1 & $0.95(0.79-1.16)$ & $0.81(0.66-0.99)$ & $0.048 *$ & 1 & $1.04(0.81-1.32)$ & $1.07(0.81-1.41)$ & $0.609 *$ \\
\hline \multicolumn{9}{|l|}{ High blood pressure } \\
\hline Prevalence (n (\%)) & $606(32.0)$ & 305 (30.6) & $289(33.7)$ & & $855(32.8)$ & $226(26.7)$ & $172(32.6)$ & \\
\hline ORs $(95 \% \mathrm{CI})$ & 1 & $0.96(0.81-1.14)$ & $0.90(0.75-1.08)$ & $0.275 *$ & 1 & $1.00(0.82-1.22)$ & $1.03(0.83-1.29)$ & $0.799 *$ \\
\hline \multicolumn{9}{|l|}{ Abdominal obesity } \\
\hline Prevalence (n (\%)) & $337(17.8)$ & 234 (23.5) & $251(29.3)$ & & $1386(53.2)$ & 450 (53.1) & $318(60.2)$ & \\
\hline ORs $(95 \%$ CI $)$ & 1 & $1.45(1.20-1.75)$ & $1.91(1.58-2.31)$ & $<0.0001^{+}$ & 1 & $1.31(1.11-1.55)$ & $1.58(1.29-1.94)$ & $<0.0001^{\dagger}$ \\
\hline \multicolumn{9}{|l|}{ Obesity } \\
\hline Prevalence (n (\%)) & $676(35.7)$ & $426(42.7)$ & $428(49.9)$ & & $1132(43.5)$ & $364(42.9)$ & $294(55.7)$ & \\
\hline ORs $(95 \%$ CI $)$ & 1 & $1.30(1.11-1.52)$ & $1.87(1.58-2.21)$ & $<0.0001^{\dagger}$ & 1 & $1.06(0.91-1.25)$ & $1.72(1.42-2.08)$ & $<0.0001^{\dagger}$ \\
\hline \multicolumn{9}{|l|}{ Severe obesity } \\
\hline Prevalence (n (\%)) & $41(2.2)$ & $33(3.3)$ & $33(3.9)$ & & $171(6.6)$ & $55(6.5)$ & $50(9.5)$ & \\
\hline ORs $(95 \%$ CI $)$ & 1 & $1.48(0.93-2.36)$ & $1.82(1.14-2.90)$ & $0.01^{\dagger}$ & 1 & $1.04(0.75-1.42)$ & $1.52(1.09-2.12)$ & $0.027^{\dagger}$ \\
\hline \multicolumn{9}{|l|}{$\begin{array}{c}\text { Metabolic syndrome } \\
\text { (No. of components) } \\
\geq 3\end{array}$} \\
\hline Prevalence (n (\%)) & $357(18.8)$ & $204(20.4)$ & $199(23.2)$ & & $804(30.9)$ & $232(27.4)$ & $176(33.3)$ & \\
\hline ORs $(95 \% \mathrm{CI})$ & 1 & $1.14(0.94-1.38)$ & $1.29(1.06-1.50)$ & $0.01^{\dagger}$ & 1 & $1.10(0.92-1.32)$ & $1.28(1.04-1.58)$ & $0.018^{\dagger}$ \\
\hline \multicolumn{9}{|l|}{$1-2$} \\
\hline Prevalence (n (\%)) & $998(52.7)$ & $521(52.2)$ & 442 (51.6) & & $1288(49.4)$ & $414(48.8)$ & $264(50.0)$ & \\
\hline ORs $(95 \%$ CI $)$ & 1 & $0.98(0.84-1.15)$ & $0.95(0.81-1.12)$ & $0.566^{\dagger}$ & 1 & $0.93(0.79-1.08)$ & $1.01(0.84-1.22)$ & $0.772^{\dagger}$ \\
\hline \multicolumn{9}{|l|}{0 (normal) } \\
\hline Prevalence (n (\%)) & $540(28.5)$ & $273(27.4)$ & $216(25.2)$ & & $513(19.7)$ & $202(23.8)$ & 88 (16.7) & \\
\hline ORs $(95 \% \mathrm{CI})$ & 1 & $0.93(0.78-1.10)$ & $0.86(0.71-1.03)$ & $0.092^{\dagger}$ & 1 & $0.98(0.81-1.20)$ & $0.70(0.54-0.91)$ & $0.022^{+}$ \\
\hline
\end{tabular}

$\mathrm{CI}$, confidence intervals; HDL, high density lipoprotein; OR, odds ratio. ORs (95\% CIs) were conducted by logistic regression model. * $p$-trend obtained with adjustment for age, body mass index, alcohol intake, smoking, exercise, education level, and income status. ${ }^{\dagger} p$-trend obtained with adjustment for age, alcohol intake, smoking, exercise, education level, and income status. 


\section{Discussion}

In this study, the association between liking for fat and metabolic syndrome was analyzed using large-scale cohort data from Korean adults. Liking for fat was associated with daily intake of vegetables, meat, added fat, and soft drinks in men and women. Liking for fat was positively linked to dietary energy and fat and inversely linked to vitamin $C$ and fiber intake. In addition, there was a significantly positive association between liking for fat and odds of obesity and metabolic syndrome.

Our study showed that liking for fat was positively associated with red meat, added fat, soft drinks and chocolate intake, and inversely associated with vegetable intake both in men and women. In addition, men and women with a stronger liking for fat tended to have higher energy and fat intake and lower fiber intake. Mejean et al. [5] found that subjects with a strong liking for fat showed higher intake of total energy, saturated fat, meat, butter, and sweetened cream desserts and lower intake of fiber, fruits, and vegetables. According to the studies of Drewnowski [25,26], a strong preference for fatty foods was associated with high fat and low fiber intake. Fat is a highly enriched source of energy, and food containing such highly concentrated energy can contribute to excessive calorie consumption. Furthermore, individuals who prefer fat may less likely to consume healthy foods, such as fruits and vegetables, because they find them less tasty. Hence, they may tend to replace healthy foods with energy-dense variants. Therefore, liking for fat is presumably related to excessive intake of energy and fat and low fiber intake. In addition, liking for fat showed a significantly positive association with moderate exercise in men. Fat liking can increase motivation to exercise for energy consumption. It was reported that exercise affects compensatory eating behavior [27]. Consistent with this result, subjects with stronger liking for fat were more likely to exercise.

In this study, liking for fat had a significantly positive association with odds for obesity in men and women. These findings are similar to a previous report [28] that French adults with higher BMIs preferred fat. In middle-aged Japanese subjects, the fat-rich and heavy taste preferences had a positive association with an increase in body weight [10]. The preference for palatable tastes such as fat could lead to excessive energy intake, which increases body weight. On the other hand, low-energy-density diets (e.g., high in dietary fiber) were related to lower body weights [29]. Diets high in fiber are associated with lower body weight and body fat, possibly because they promote satiation, decrease absorption of macronutrients, and alter the secretion of gut hormones [30]. Our results have shown that liking for fat was related to low fiber intake and high energy and fat intake. This dietary intake can have long-term consequences on the risk of developing obesity. If all of these factors are taken into consideration, it can be presumed that there is a positive association between liking for fat and the obesity.

Liking for fat also appeared to be significantly positively associated with the odds of metabolic syndrome and abdominal obesity in both men and women. Mendoza et al. [31] reported that a highly energy-dense diet was associated with increased abdominal obesity and prevalence of metabolic syndrome. Dietary factors, particularly energy and fat intake, are strongly related to body fat deposition. Excess body fat reduces insulin sensitivity, thereby increasing the prevalence of the metabolic diseases [32]. The presence of insulin resistance may cause the development of type 2 diabetes [33]. Insulin resistance tends to interfere with glucose disposal and predisposes one to hyperinsulinemia and elevated plasma glucose. However, there was a significant inverse association between liking for fat and the odds of high fasting glucose in men. Men with stronger liking for fat tend to have higher intake of fat, yet significantly lower intake of carbohydrates as compared to subjects with lower liking for fat. Although there is conflicting evidence on the influence of carbohydrate intake on insulin sensitivity [34], a previous intervention study reported that after 6 months on a low-carbohydrate and high-fat diet, insulin sensitivity improved among obese subjects [35]. It is speculated that decreased carbohydrate intake in subjects with stronger liking for fat may have partially contributed to low odds of high fasting glucose.

Meanwhile, in metabolic syndrome patients, the numbers of individuals in the Dislike, Neither like nor dislike, and Like groups were 357 (47.0\%), 204 (26.8\%), and 199 (26.2\%) for men, and 804 (66.3\%), $232(19.1 \%)$, and $176(14.5 \%)$ for women, respectively. The proportion of the Like group with metabolic 
syndrome was expected to be higher than that of the Neither like nor dislike group (men: 658 (22.0\%), women: $352(12.7 \%)$ ), but there was no significant difference. It is suggested that the liking for fat is not an independent predictor of metabolic syndrome, but rather that liking for fat and various other factors affect metabolic syndrome. Indeed, various influencing factors of the metabolic syndrome have been reported [36]. In the present study, a sensory liking for fat is proposed as one of the risk factors that affect health, with an investigation of the relationship between sensory fat liking and the risk of metabolic syndrome. There was a significant positive association between liking for fat and the risk of metabolic syndrome.

Sensory liking measures are intended to rapidly and accurately assess dietary behaviors [37]. According to basic research in cognition, recalling food likes/dislikes may be simpler and more accurate than recalling intake [38,39]. Because they require less cognition, sensory liking measures may be less biased by cognitive control than reporting dietary intake (i.e., dietary restraint). In this study, liking for fat was positively associated with fatty food consumption and risk of metabolic syndrome. These findings highlight the need to consider the influence of sensory liking in the management and prevention of metabolic disorders. Taking into account an individual's liking may help dietitians and practitioners provide effective dietary counseling while supporting guidelines designed to reduce metabolic syndrome.

A liking for fat could influence the intake of both fatty-salty foods and fatty-sweetened foods [5]. Sensory properties of salt or sugar combined with fat may improve pleasure of meals and snacks and might therefore lead to higher consumption $[40,41]$. In addition, there is a report that the fat-salt sensation is strongly favored by heavy drinkers as compared to abstainers or irregular alcohol consumers [42]. Thus, creating an additional risk factor for obesity and health-related problems. Furthermore, genetic variation may also affect human fat sensation and consumption behavior. Sensitivity to the bitter taste has been shown to be genetically altered and positively associated with perceived intensity of fat and sugar, resulting in decreased liking for fatty or sweetened foods [43], whereas it has been associated with greater perceived intensity and liking for salt [44]. In a previous study, a representative fat receptor gene, the CD36 gene polymorphism was reported to be associated with the perceived creaminess of salad dressings and the preference of certain types of fat in African Americans [45]. If such results are taken into consideration, it is postulated that various factors could modify the relationship between fat liking and metabolic disease.

There are some limitations in this study. As the relationship between fat liking and metabolic syndrome was analyzed through a cross-sectional study design, causality cannot be confirmed. In addition, dietary intake was analyzed through the SQFFQ and thus there may be an inaccurate quantification of actual intake amounts. However, despite such limitations, this is the first study to our knowledge to analyze the biochemical variables of subjects, such as total cholesterol, HDL cholesterol, triglyceride, and fasting glucose, and to identify associations between liking for fat and the metabolic syndrome in a large-scale population-based study in Korea.

\section{Conclusions}

This study of middle-aged Korean individuals demonstrated that liking for fat was positively associated with the odds of metabolic syndrome. In addition, subjects with a stronger liking for fat showed higher intake of energy and fat and lower intake of fiber. These findings suggested that the sensory liking for fat may be associated with the increased odds of metabolic syndrome in Korean adults. Although we believe that further longitudinal follow-up studies are needed, we expect that the findings of the study can be utilized as a guideline for diets designed to reduce metabolic disorders.

Supplementary Materials: The following are available online at http:/ / www.mdpi.com/2072-6643/10/7/877/s1, Table S1: Un-adjusted odds ratios (95\% confidence intervals) for obesity and metabolic syndrome according to level of liking for fat.

Author Contributions: Y.K. and Y.S. created the study concept and design; H.P. and Y.S. performed the statistical analysis; Y.K., H.P., Y.S. and O.K. conducted the data interpretation and discussion; Y.S. drafted the manuscript. 
Acknowledgments: This research was supported by the Bio \& Medical Technology Development Program of the National Research Foundation (NRF) funded by the Ministry of Science \& ICT (NRF-2012M3A9C4048761) and Brain Korea 21 Plus Project of the National Research Foundation funded by the Ministry of Education of Korea (22A20130012143). Bioresources were provided by the National Biobank of Korea, Center for Disease Control and Prevention, Republic of Korea (4845-301, 4851-302, and -307).

Conflicts of Interest: The authors declare no conflict of interest.

\section{References}

1. Ford, E.S. Risks for all-cause mortality, cardiovascular disease, and diabetes associated with the metabolic syndrome. Diabetes Care 2005, 28, 1769-1778. [CrossRef] [PubMed]

2. Park, Y.W.; Zhu, S.; Palaniappan, L.; Heshka, S.; Carnethon, M.R.; Heymsfield, S.B. The metabolic syndrome: Prevalence and associated risk factor findings in the US population from the Third National Health and Nutrition Examination Survey, 1988-1994. Arch. Intern. Med. 2003, 163, 427-436. [CrossRef] [PubMed]

3. Grundy, S.M.; Cleeman, J.I.; Daniels, S.R.; Donato, K.A.; Eckel, R.H.; Franklin, B.A.; Gordon, D.J.; Krauss, R.M.; Savage, P.J.; Smith, S.C.; et al. Diagnosis and management of the metabolic syndrome. Circulation 2005, 112, 2735-2752. [CrossRef] [PubMed]

4. Alberti, K.G.; Zimmet, P.; Shaw, J. IDF Epidemiology Task Force Consensus Group. The metabolic syndrome-A new worldwide definition. Lancet 2005, 366, 1059-1062. [CrossRef]

5. Méjean, C.; Deglaire, A.; Kesse-Guyot, E.; Hercberg, S.; Schlich, P.; Castetbon, K. Association between intake of nutrients and food groups and liking for fat (The Nutrinet-Sante Study). Appetite 2014, 78, 147-155. [CrossRef] [PubMed]

6. Hercberg, S.; Chat-Yung, S.; Chauliac, M. The French national nutrition and health program: 2001-2006-2010. Int. J. Public Health 2008, 53, 68-77. [CrossRef] [PubMed]

7. Mela, D.J. Eating for pleasure or just wanting to eat? Reconsidering sensory hedonic responses as a driver of obesity. Appetite 2006, 47, 10-17. [CrossRef] [PubMed]

8. American Institute for Cancer Research/World Cancer Research Fund. Food, Nutrition, Physical Activity and the Prevention of Cancer: A Global Perspective; American Institute for Cancer Research: Washington, DC, USA, 2007.

9. World Health Organization. Diet, Nutrition and the Prevention of Chronic Diseases; No. 916; WHO: Geneva, Switzerland, 2003.

10. Matsushita, Y.; Mizoue1, T.; Takahashi, Y.; Isogawa, A.; Kato, M.; Inoue, M.; Noda, M.; Tsugane, S. Taste preferences and body weight change in Japanese adults: The JPHC Study. Int. J. Obes. 2009, 33, 1191-1197. [CrossRef] [PubMed]

11. Drewnowski, A.; Brunzell, J.D.; Sande, K.; Iverius, P.H.; Greenwood, M.R.C. Sweet Tooth Reconsidered: Taste responsiveness in human obesity. Physiol. Behav. 1985, 35, 617-622. [CrossRef]

12. Lampuré, A.; Castetbon, K.; Deglaire, A.; Schlich, P.; Péneau, S.; Hercberg, S.; Méjean, C. Associations between liking for fat, sweet or salt and obesity risk in French adults: A prospective cohort study. Int. J. Behav. Nutr. Phys. Act. 2016, 13, 74. [CrossRef] [PubMed]

13. Rolls, B.J;; Drewnowski, A.; Ledikwe, J.H. Changing the energy density of the diet as a strategy for weight management. J. Am. Diet. Assoc. 2005, 105, S98-S103. [CrossRef] [PubMed]

14. Lim, S.; Jang, H.C.; Lee, H.K.; Kim, K.C.; Park, C.; Cho, N.H. A rural-urban comparison of the characteristics of the metabolic syndrome by gender in Korea: The Korean Health and Genome Study (KHGS). J. Endocrinol. Investig. 2006, 29, 313-319. [CrossRef] [PubMed]

15. Willett, W. Nutritional Epidemiology, 2nd ed.; Oxford University Press: New York, NY, USA, 1998; pp. $273-301$. ISBN 978-0-19-975403-8.

16. Ahn, Y.; Lee, J.E.; Paik, H.Y.; Lee, H.K.; Jo, I.; Kimm, K. Development of a semi-quantitative food frequency questionnaire based on dietary data from the Korea National Health and Nutrition Examination Survey. Nutr. Sci. 2003, 6, 173-184.

17. Ahn, Y.; Lee, J.E.; Cho, N.H.; Shin, C.; Park, C.; Oh, B.S.; Kimm, K. Validation and calibration of semi-quantitative food frequency questionnaire: With participants of the Korean Health and Genome Study. Korean J. Community Nutr. 2004, 9,'173-182.

18. Korean Nutrition Society. Appendix III. Food composition and nutrition table. In Recommended Dietary Allowances for Koreans, 7th ed.; Korean Nutrition Society (KNS): Seoul, Korea, 2000; pp. 259-464. 
19. Shin, Y.; Lee, S.; Kim, Y. Sweet preference associated with the risk of hypercholesterolemia among middle-aged women in Korea. J. Atheroscler. Thromb. 2018. [CrossRef] [PubMed]

20. World Health Organization. The Asia-Pacific Perspective: Redefining Obesity and Its Treatment; Health Communications Australia: Sydney, Australia, 2000; pp. 15-21.

21. Alberti, K.G.; Eckel, R.H.; Grundy, S.M.; Zimmet, P.Z.; Cleeman, J.I.; Donato, K.A.; Fruchart, J.C.; James, W.P.; Loria, C.M.; Smith, S.C. Harmonizing the metabolic syndrome: A joint interim statement of the International Diabetes Federation Task Force on Epidemiology and Prevention; National Heart, Lung, and Blood Institute; American Heart Association; World Heart Federation; International Atherosclerosis Society; and International Association for the Study of Obesity. Circulation 2009, 120, 1640-1645. [CrossRef] [PubMed]

22. Matthews, D.R.; Hosker, J.P.; Rudenski, A.S.; Naylor, B.A.; Treacher, D.F.; Turner, R.C. Homeostasis model assessment: Insulin resistance and $\beta$-cell function from fasting plasma glucose and insulin concentrations in man. Diabetologia 1985, 28, 412-419. [CrossRef] [PubMed]

23. Friedewald, W.T.; Levy, R.I.; Fredrickson, D.S. Estimation of the concentration of low-density lipoprotein cholesterol in plasma, without use of the preparative ultracentrifuge. Clin. Chem. 1972, 18, 499-502. [PubMed]

24. Altman, D.G.; Bland, J.M. Standard deviations and standard errors. BMJ 2005, 331, 903. [CrossRef] [PubMed]

25. Drewnowski, A.; Hann, C.; Henderson, S.A.; Gorenflo, D. Both food preferences and food frequency scores predict fat intakes of women with breast cancer. J. Am. Diet. Assoc. 2000, 100, 1325-1333. [CrossRef]

26. Drewnowski, A.; Hann, C. Food preferences and reported frequencies of food consumption as predictors of current diet in young women. Am. J. Clin. Nutr. 1999, 70, 28-36. [CrossRef] [PubMed]

27. King, N.A.; Snell, L.; Smith, R.D.; Blundell, J.E. Effects of short-term exercise on appetite responses in unrestrained females. Eur. J. Clin. Nutr. 1996, 50, 663-667. [PubMed]

28. Deglaire, A.; Méjean, C.; Castetbon, K.; Kesse-Guyot, E.; Hercberg, S.; Schlich, P. Associations between weight status and liking scores for sweet, salt and fat according to the gender in adults (The Nutrinet-Santé study). Eur. J. Clin. Nutr. 2015, 69, 40-46. [CrossRef] [PubMed]

29. Garg, A.; Bantel, J.P.; Henry, R.R.; Coulston, A.M.; Griver, K.A.; Raatz, S.K.; Brinkley, L.; Chen, Y.D.; Grundy, S.M.; Huet, B.A.; et al. Effects of varying carbohydrate content of diet in patients with non-insulin-dependent diabetes mellitus. JAMA 1994, 271, 1421-1428. [CrossRef] [PubMed]

30. Slavin, J.L. Dietary fiber and body weight. Nutrition 2005, 21, 411-418. [CrossRef] [PubMed]

31. Mendoza, J.A.; Drewnowski, A.; Christakis, D.A. Dietary energy density is associated with obesity and the metabolic syndrome in US adults. Diabetes Care 2007, 30, 974-979. [CrossRef] [PubMed]

32. Despres, J.P. Abdominal obesity as important component of insulin-resistance syndrome. Nutrition 1993, 9, 452-459. [PubMed]

33. Zimmet, P.; Dowse, G.; Bennett, P.H. Hyperinsulinemia is a predictor of non-insulin-dependent diabetes mellitus. Diabetes. Metab. Rev. 1991, 17, 101-108.

34. Samaha, F.F.; Iqbal, N.; Seshadri, P.; Chicano, K.L.; Daily, D.A.; McGrory, J.; Williams, T.; Williams, M.; Gracely, E.J.; Stern, L. A low-carbohydrate as compared with a low-fat diet in severe obesity. N. Engl. J. Med. 2003, 348, 2074-2081. [CrossRef] [PubMed]

35. Ludwig, D.S.; Pereira, M.A.; Kroenke, C.H.; Hilner, J.E.; Van Horn, L.; Slattery, M.L.; Jacobs, D.R., Jr. Dietary fiber, weight gain, and cardiovascular disease risk factors in young adults. JAMA 1999, 282, 1539-1546. [CrossRef] [PubMed]

36. Lee, W.Y.; Jung, C.H.; Park, J.S.; Rhee, E.J.; Kim, S.W. Effects of smoking, alcohol, exercise, education, and family history on the metabolic syndrome as defined by the ATP III. Diabetes Res. Clin. Pract. 2005, 67, 70-77. [CrossRef] [PubMed]

37. Duffy, V.B.; Lanier, S.A.; Hutchins, H.L.; Pescatello, L.S.; Johnson, M.K.; Bartoshuk, L.M. Food preference questionnaire as a screening tool for assessing dietary risk of cardiovascular disease within health risk appraisals. J. Am. Diet. Assoc. 2007, 107, 237-245. [CrossRef] [PubMed]

38. Johnson, M.K.; Kim, J.K.; Risse, G. Do alcoholic Korsakoff's syndrome patients acquire affective reactions? J. Exp. Psychol. Learn. Mem. Cogn. 1985, 11, 22-36. [CrossRef] [PubMed]

39. Johnson, M.; Multhaup, K. Emotion and MEM. In The Handbook of Emotion and Memory: Current Research and Theory; Christianson, S.A., Ed.; Erlbaum: New York, NY, USA, 1992; pp. 33-66.

40. Emmett, P.M.; Heaton, K.W. Is extrinsic sugar a vehicle for dietary fat? Lancet 1995, 345, 1537-1540. [CrossRef]

41. Kanarek, R.B.; Ryu, M.; Przypek, J. Preferences for foods with varying levels of salt and fat differ as a function of dietary restraint and exercise but not menstrual cycle. Physiol. Behav. 1995, 57, 821-826. [CrossRef] 
42. Lampuré, A.; Deglaire, A.; Schlich, P.; Castetbon, K.; Péneau, S.; Hercberg, S.; Méjean, C. Liking for fat is associated with sociodemographic, psychological, lifestyle and health characteristics. Br. J. Nutr. 2014, 112, 1353-1363. [CrossRef] [PubMed]

43. Hayes, J.E.; Duffy, V.B. Oral sensory phenotype identifies level of sugar and fat required for maximal liking. Physiol. Behav. 2008, 95, 77-87. [CrossRef] [PubMed]

44. Hayes, J.E.; Sullivan, B.S.; Duffy, V.B. Explaining variability in sodium intake through oral sensory phenotype, salt sensation and liking. Physiol. Behav. 2010, 100, 369-380. [CrossRef] [PubMed]

45. Keller, K.L.; Liang, L.C.; Sakimura, J.; May, D.; Belle, C.; Breen, C.; Driggin, E.; Tepper, B.J.; Lanzano, P.C.; Deng, L.; et al. Common variants in the CD36 gene are associated with oral fat perception, fat preferences, and obesity in African Americans. Obesity 2012, 20, 1066-1073. [CrossRef] [PubMed]

2018 by the authors. Licensee MDPI, Basel, Switzerland. This article is an open access article distributed under the terms and conditions of the Creative Commons Attribution (CC BY) license (http://creativecommons.org/licenses/by/4.0/). 